\title{
Diet, risk of obesity and socioeconomic circumstances of individuals in the UK: A seemingly unrelated approach
}

\author{
DAMILOLA OLAJIDE ${ }^{1, *} \&$ ANNE LUDBROOK ${ }^{2}$ \\ 11.olajide@abdn.ac.uk, University of Aberdeen, UK \\ 2a.ludbrook@abdn.ac.uk, University of Aberdeen, UK
}

\begin{abstract}
Understanding the link between diet, risk of obesity and the underlying socioeconomic circumstances of the individual is useful for health promotion and improvement interventions. In this study, we examine the socioeconomic factors that jointly affect food consumption choices and risk of obesity. We analyse the National Dietary and Nutrition Survey (2000/01) of adults aged 19-64 years living in private households in the UK, using a health production framework. The information on the complete food history on individuals in the previous week are used to create eight common food groups. The seemingly unrelated regression method is used to estimate a system of linear risk of obesity (as measured by Body Mass Index) and eight diet equations with error terms that are correlated across equations for a given individual, but are uncorrelated across individuals. Our findings indicate that the socioeconomic factors (e.g. income and education) associated with sources of healthy eating differ. While increasing household purchasing power may be more effective for increasing consumption of healthier foods such as fruit and vegetables, more knowledge and information about healthy eating may be more effective for cutting down on consumption of less healthy foods (e.g. preserves and savoury foods). An understanding of these different healthy eating contexts is essential for the development of effective targeted food based policies aimed at reducing the risk of obesity.
\end{abstract}

Keywords: Health production; Body Mass Index; Dietary patterns; Seemingly unrelated regression

JEL Classification: I12, I18, I19

\section{Introduction}

The increased prevalence of overweight and obesity over the past two decades has led to descriptions of an obesity 'worldwide epidemic' with major public health concerns. According to the World Health Organisation, more than a billion adults are overweight, at least a third of whom are clinically obese. Overweight and obesity are a major contributor to the burden of chronic diseases, including coronary heart disease, hypertension, stroke, type 2 diabetes, and certain types of cancer, and disability (WHO 2004).

There are significant health and socioeconomic costs of overweight and obesity. The UK House of Commons Health Select Committee (HCHSC) estimated the total annual costs of overweight and obesity in England in 2002 at nearly $£ 7$ billion (HCHSC 2004). In financial terms, the total impact of obesity on employment has been found to be 
as much as $£ 10$ billion (McCormack and Stone 2007). In addition, overweight and obesity also impose a considerable financial burden on the healthcare system. During 2003/2004, overweight and obesity was directly responsible for over $7 \%$ of morbidity and mortality, with the direct cost to the National Health Services (NHS) estimated at around $£ 3.2$ billion (Allender and Rayner 2007).

The link between obesity and diet is well established. There is an increasing consensus that the obesity epidemic particularly in developed countries, has been driven largely by the improvement in social and economic circumstances of individuals such as rising incomes, which had resulted from the urbanisation and globalisation process. This has resulted in nutrition transition with diets rich in complex carbohydrates being replaced by increased consumption of calorie dense foods high in fats and sugar coupled with undertaking less physically demanding activities (Costa-font and Gil 2005, Chou et al 2004, WHO 2004, Wang et al 2002, Lakdawalla and Philipson 2002).

Diet is a fundamental input in the health production function. However, individuals make dietary decisions based on their circumstances including socioeconomic, physiological, and psychological, without necessarily having to consider the health implications. This may be because individuals have imperfect information about the risk and consequences of their dietary behaviour. Such information may include the calorie content of different forms of food items or the link between diet and weight gain (McCormick and Stone 2007). In some societies, food consumption is a marker of social status, an act of pleasure and convenience (DOH 2003), which do not necessarily relate to understanding nutrient values of a particular diet.

In previous studies, diet and obesity have been associated separately with socioeconomic circumstances of the individual. Socioeconomic indicators such as income, education, social class, and working conditions feature prominently in studies of the socioeconomic determinants of dietary behaviour (e.g. Moreira and Padrao 2004, Yang et al 2005, Whichelow and Prevost 1996). These factors also tend to feature in studies of socioeconomic determinants of obesity (e.g. Moreira and Padrao 2006, Wamala et al 1997). However, attempts at examining the interrelationship between diet, obesity and socioeconomic circumstances of the individual in a single framework have met with limited success. For example, Moreira and Padrao (2006) examined the socioeconomic and dietary determinants of obesity using Portuguese data. The diet-obesity relationship part of the study yielded inconclusive results. The authors attributed this to an inability to assess the effects of diet on obesity due to limited information on specific food items. While recognising the possibility of obesity feeding back into diet, the authors suggested a framework linking the relationship between food consumption and obesity, and linking food items to socioeconomic characteristics of the individual.

The present study aims to contribute to a better understanding of the interrelationship between diet, risk of obesity, and socioeconomic circumstances of individuals. We conceptualise diet and the risk of obesity as jointly determined by similar underlying socioeconomic factors. This allows us to use the seemingly unrelated regression approach, whereby the error terms of the diet and risk of obesity equations are correlated for a given individual, but are uncorrelated across individuals. The conjecture here is that if unhealthy diets are associated with socioeconomically disadvantaged populations, then this group of individuals can be expected to be at greater risk of obesity. Treating diet and risk of obesity as jointly determined has an advantage of addressing endogeneity and unobserved heterogeneity problems often encountered in similar analyses and ultimately improve the efficiency of the estimates (e.g. Costa-font and Gil 2005). An implication of this approach for health promotion and improvement interventions is that, those groups of individuals in the population at greater risk of obesity can be identified by 
their socioeconomic circumstances and then targeted for education on healthy eating and disease prevention.

The remaining part of the paper is organised as follows. The next section (Section 2) presents a brief overview of the conceptual framework and the econometric specification linking diet-obesity relationship to socioeconomic circumstances of the individual. Section 3 presents the description of the data set and the variables used in the analysis. The results are presented in Section 4. Section 5 discusses the key findings and the conclusions are provided in Section 6.

\section{Diet, risk of obesity and socioeconomic circumstances of individuals}

\subsection{Conceptual framework}

The Grossman (1972a and 1972b) framework for health capital and demand for health provide the background for the conceptual framework. The framework as adopted in the present study is based on certain key assumptions; firstly, an individual is assumed to maximise utility subject to constraints provided by a health production function and dietary input into the production function. Secondly, the efficiencies of producing health from dietary intake and vice-versa are each conditioned on socioeconomic factors. Also, health is allowed to feedback into dietary intake, in which case individuals consume foods based on their current health. Most nutrition and epidemiology studies ignore this endogeneity issue.

In its basic formulation, the health production framework will also contain an income constraint such that income equals expenditure on food and non-food inputs (e.g. Variyam et al 1996, Costa-Font and Gil 2005). In the present study, however, we take the income constraint as given and assume constant prices. These two assumptions follow because the focus is on dietary choices made at a given point in time, during which we assume limited price variation. Also, constant prices can be reasonably assumed, especially where analysis employs cross-sectional data (Nayga et al 1999). We employ cross sectional data in the present study.

\subsection{Econometric specification}

The health production framework can be stated as a system of linear equations of the form:

$$
H_{i}=\alpha_{0}+\alpha_{1} D_{i k}+\alpha_{2} X_{i}+e_{i 1}
$$

and

$$
D_{i k}=\beta_{0}+\beta_{1} H_{i}+\beta_{2} X_{i}+e_{i 2}
$$

where $D_{i k}$ is the $k^{\text {th }}$ diet equation; $X$ is a vector of socioeconomic variables that affect both health and diet; and $e_{i 1}, e_{i 2}$ are the usual error terms ${ }^{1} . X$ 's are treated as exogenous variables, assumed to be uncorrelated with the error terms but generally, $D_{i k}$ and $e_{i 1}$ are correlated because the former is endogenous in Equation (1). The reduced form is to solve for the endogeneity of diet $k$.

\footnotetext{
${ }^{1}$ There are $k$ error terms in Equation (2).
} 
Assuming that $\alpha_{1} \beta_{1} \neq 1$ and substituting for health and $k^{\text {th }}$ diet in Equations (1) and (2), the respective reduced-form health and $k^{\text {th }}$ diet equations can be stated as:

$$
H_{i}=\lambda_{0}+\lambda_{1} X_{i}+u_{i}
$$

and

$$
D_{i k}=\delta_{0}+\delta_{1} X_{i}+v_{i k}
$$

where in (3);

$$
\lambda_{0}=\frac{\alpha_{0}+\alpha_{1} \beta_{0}}{\left(1-\alpha_{1} \beta_{1}\right)} ; \quad \lambda_{1}=\frac{\alpha_{1} \beta_{2}}{\left(1-\alpha_{1} \beta_{1}\right)} X_{i} ; \text { and } u_{i}=\frac{e_{1}+\alpha_{1} e_{2}}{\left(1-\alpha_{1} \beta_{1}\right)}
$$

and for the $k^{\text {th }}$ equation in (4);

$$
\delta_{0}=\frac{\beta_{0}+\beta_{1} \alpha_{0}}{\left(1-\beta_{1} \alpha_{1}\right)} ; \delta_{1}=\frac{\beta_{2}}{\left(1-\beta_{1} \alpha_{1}\right)} X ; \text { and } v_{i k}=\frac{e_{2}+\beta_{1} e_{1}}{\left(1-\beta_{1} \alpha_{1}\right)}
$$

All of the equations in (3) and (4) are linked by the fact that their error terms are correlated across equations for the $i^{\text {th }}$ individual, but are uncorrelated across individuals. In principle, equations (3) and the $k^{\text {th }}$ equation in (4) provide an example of the Zellner (1962) Seemingly Unrelated Regression (SUR) ${ }^{2}$. In practice, however, since the right hand side variables are the same across all of the equations (i.e. $X_{\mathrm{i}}=X_{i k}$ for all $i$ and $k$ ), an equation-by-equation Ordinary Least Squares (OLS) estimation of the $\lambda$ and $\delta$ parameters is consistent (Cameron and Trivedi 2009).

\section{Data and variables}

\subsection{Data source}

The data for this study came from the 2000/2001 UK National Diet and Nutrition Survey (NDNS). The NDNS is a nationally representative survey of 1,724 individuals aged 19-64 living in private households in the UK. Respondents were randomly selected into the sample by selecting addresses from the small users' Postcode Address File, stratified by 1991 Census variables. Eligibility was limited to people in the defined age range and not being pregnant or breastfeeding at the time of survey (NDNS 2002).

The NDNS survey provides a comprehensive, cross-sectional information on food items consumed by the individual in the previous week, as well as information on physical and anthropometric measurements obtained during nurse visits. The dataset also contains information on the demographic and socioeconomic circumstances of the individual respondents.

\footnotetext{
${ }^{2}$ SUR is a Feasible Generalised Least Squares (FGLS) estimation technique. FGLS is a family of Generalised Least Square estimations of a system of linear equations when the error terms are corrected.
} 


\subsection{Dietary outcome variables (Food groups)}

The NDNS survey provides comprehensive information on 112 food items consumed by the individual in the previous week. The quantity consumed of each food item was collected through both a questionnaire and a seven-day weighed intake record kept by the individual respondents. Using the NDNS (2002) approach, we used the diet information to create eight common food groups namely: Cereals and cereal products; Milk and milk products; Fat spreads; Meat and meat products; Fish and fish products; Fruit and vegetables; and Sugars, preserves and savoury foods. Our classification of the food items into food groups is consistent with the 'healthy' and 'less healthy' foods used for generating a healthy eating index from the Scottish Health Survey (e.g. Eberth and Smith 2010). Whereas items under 'Fruit and vegetables' and 'Fish and fish products' can be classified as 'healthy', those under 'Sugars, preserves and savoury foods' can be classified as 'less healthy'.

Table 1 presents the distribution of the food groups by gender and age (in kilograms per week) $)^{3}$. There are both age and gender dimensions to the pattern of food consumption in the sample. Three points are worth noting. First, males consumed higher quantities across all of the food groups, with a few exceptions where younger men appear to be consuming less of healthy items.

Second, there is an age gradient in the decreasing consumption of 'Sugars, preserves, and savoury foods', and 'Meat and meat products' food groups (less healthy), and increasing consumption of 'Fruit and vegetables' and 'Fish and fish products'. Third, whilst the consumption of 'Sugars, preserves, and savoury foods' dominates amongst adults aged 19-49 years, consumption of 'Fruit and vegetables' dominates amongst adults aged 50-64 years. These patterns appear to indicate that, ceteris paribus, older adults in this sample had healthier diets.

\subsection{Health, demographic and socioeconomic variables}

Table 2 presents the descriptive statistics of the health, demographic and socioeconomic variables. The health outcome of the individual was measured by Body Mass Index $(\mathrm{BMI})^{4}$. BMI is a widely accepted indicator of risk of obesity (e.g. Costa-Font and Gil 2005, Moreira and Padrao 2006). It is less likely that under-reporting of anthropometric measures might arise in the NDNS data since these measures were undertaken by visiting nurses. The average individual in the sample is slightly overweight, with BMI at approximately 26.8 .

The demographic variables included were age and gender. The average age in the sample is a little over 42 years and males were in minority $(44.4 \%)$. The socioeconomic variables included were marital status, educational qualifications, employment status, occupation-based social status, annual household income, household size and receipt of income/employment benefits. During econometric estimation, we alternated between educational qualifications, occupation-based social status and annual household income, as these variables may be correlated with each other. The wave dummies indicate that the number of respondents in the sample increased overtime, with the majority interviewed during Jan-June 2001 (approximately 58.8\%).

\footnotetext{
${ }^{3}$ The total quantity of food consumption was originally collected in grams per week. In order to reduce large figures, we divided the total amount by 1000 to give the figures in Kilograms per week

${ }^{4}$ Since $\mathrm{BMI}=$ weight $/$ height $^{2}$ does not take into account body composition of body fat distribution, it may fail to accurately predict obesity among athletic and muscular individuals (Costa-Font and Gil 2005).
} 
Table 1: Distribution of food groups by gender and age (total intake - kg/week)

\begin{tabular}{|c|c|c|c|c|c|c|}
\hline \multicolumn{7}{|c|}{ Age groups } \\
\hline Gender & Food groups ${ }^{1}$ & $\begin{array}{l}\text { Aged } \\
19-24 \\
\end{array}$ & $\begin{array}{l}\text { Aged } \\
25-34 \\
\end{array}$ & $\begin{array}{l}\text { Aged } \\
35-49 \\
\end{array}$ & $\begin{array}{c}\text { Aged } \\
50-64 \\
\end{array}$ & Total \\
\hline \multirow[t]{9}{*}{ Male } & & \multicolumn{5}{|c|}{ (kg on average per week) } \\
\hline & Cereals/cereal products & 2.369 & 2.721 & 2.494 & 2.350 & 2.486 \\
\hline & Milk/milk products & 1.875 & 2.770 & 2.918 & 2.930 & 2.808 \\
\hline & Eggs/egg products & 0.173 & 0.207 & 0.206 & 0.245 & 0.216 \\
\hline & Fat spreads & 0.145 & 0.137 & 0.148 & 0.162 & 0.150 \\
\hline & Meat/meat products & 2.052 & 2.083 & 1.998 & 1.770 & 1.948 \\
\hline & Fish/fish products & 0.189 & 0.244 & 0.317 & 0.420 & 0.324 \\
\hline & Fruit \& Vegetables & 2.037 & 2.769 & 3.591 & 4.120 & 3.463 \\
\hline & Sugars \& savoury & 6.780 & 5.420 & 4.404 & 3.515 & 4.525 \\
\hline \multicolumn{7}{|l|}{ Female } \\
\hline & Cereals/cereal products & 1.831 & 1.783 & 1.801 & 1.732 & 1.779 \\
\hline & Milk/milk products & 1.996 & 2.066 & 2.590 & 2.827 & 2.498 \\
\hline & Eggs/egg products & 0.127 & 0.125 & 0.163 & 0.189 & 0.159 \\
\hline & Fat spreads & 0.077 & 0.088 & 0.102 & 0.111 & 0.100 \\
\hline & Meat/meat products & 1.347 & 1.179 & 1.428 & 1.201 & 1.298 \\
\hline & Fish/fish products & 0.208 & 0.199 & 0.294 & 0.408 & 0.301 \\
\hline & Fruit \& Vegetables & 2.276 & 2.873 & 3.366 & 4.079 & 3.385 \\
\hline & Sugars \& savoury & 5.882 & 4.565 & 3.436 & 3.126 & 3.790 \\
\hline \multicolumn{7}{|l|}{ All } \\
\hline & Cereals/cereal products & 2.067 & 2.188 & 2.109 & 2.013 & 2.093 \\
\hline & Milk/milk products & 1.943 & 2.370 & 2.736 & 2.874 & 2.636 \\
\hline & Eggs/egg products & 0.147 & 0.161 & 0.182 & 0.214 & 0.185 \\
\hline & Fat spreads & 0.107 & 0.109 & 0.122 & 0.135 & 0.122 \\
\hline & Meat/meat products & 1.656 & 1.569 & 1.681 & 1.460 & 1.587 \\
\hline & Fish/fish products & 0.199 & 0.219 & 0.305 & 0.413 & 0.311 \\
\hline & Fruit \& Vegetables & 2.171 & 2.828 & 3.466 & 4.097 & 3.419 \\
\hline & Sugars \& savoury & 6.276 & 4.934 & 3.866 & 3.303 & 4.117 \\
\hline
\end{tabular}

Note: ${ }^{1}$ Appendix G in NDNS (2002) provides details of individual food items under each food group. 
Table 2: Summary statistics of health, demographic and socioeconomic variables

\begin{tabular}{|c|c|c|c|c|}
\hline Variable & Mean & Std. Dev. & Min & Max \\
\hline BMI & 26.820 & 5.030 & 17.892 & 57.330 \\
\hline Age & 42.104 & 12.115 & 19 & 64 \\
\hline Age 19 to $24^{*}$ & 0.081 & 0.272 & 0 & 1 \\
\hline Age 25 to 34 & 0.215 & 0.411 & 0 & 1 \\
\hline Age 35 to 44 & 0.282 & 0.450 & 0 & 1 \\
\hline Age 45 to 54 & 0.227 & 0.419 & 0 & 1 \\
\hline Age 55 to 64 & 0.194 & 0.396 & 0 & 1 \\
\hline Gender $($ Male $=1)$ & 0.444 & 0.497 & 0 & 1 \\
\hline Single $^{*}$ & 0.278 & 0.448 & 0 & 1 \\
\hline Married/cohabiting & 0.522 & 0.500 & 0 & 1 \\
\hline Divorced/widowed/separated & 0.200 & 0.400 & 0 & 1 \\
\hline No Educational qualification ${ }^{*}$ & 0.208 & 0.406 & 0 & 1 \\
\hline $\begin{array}{l}\text { Lower- School leaving cert, 'O' grade, GCSE. } \\
\text { Lower mid level - SVQ, 'A' level, ONC, }\end{array}$ & 0.360 & 0.480 & 0 & 1 \\
\hline $\mathrm{OND} / \mathrm{C} \& \mathrm{G}$, etc. & 0.104 & 0.305 & 0 & 1 \\
\hline Upper mid level - HNC, HND, etc. & 0.142 & 0.349 & 0 & 1 \\
\hline University degree or equivalent & 0.186 & 0.389 & 0 & 1 \\
\hline LowHInc - income $<£ 14,000 \mathrm{pa}^{*}$ & 0.314 & 0.464 & 0 & 1 \\
\hline MidHInc - income $£ 14,000$ - $£ 30,000$ pa & 0.368 & 0.482 & 0 & 1 \\
\hline UpperHInc - income $£ 30,000+$ pa & 0.318 & 0.466 & 0 & 1 \\
\hline Social status1 - semi/unskilled/other ${ }^{5}$ & 0.240 & 0.427 & 0 & 1 \\
\hline Social status2 - skilled & 0.396 & 0.489 & 0 & 1 \\
\hline Social status 3 - professional/managerial & 0.364 & 0.481 & 0 & 1 \\
\hline Home owner & 0.739 & 0.439 & 0 & 1 \\
\hline Household size & 2.636 & 1.321 & 1 & 10 \\
\hline Living alone & 0.200 & 0.400 & 0 & 1 \\
\hline Receipt of any benefits & 0.177 & 0.382 & 0 & 1 \\
\hline Wave1: July-Sept 2000 & 0.189 & 0.391 & 0 & 1 \\
\hline Wave2: Oct-Dec 2000 & 0.223 & 0.417 & 0 & 1 \\
\hline Wave3: Jan-Mar 2001 & 0.248 & 0.432 & 0 & 1 \\
\hline Wave4: Apr-June 2001 & 0.340 & 0.474 & 0 & 1 \\
\hline
\end{tabular}

${ }^{*}$ Reference categories for estimation

\section{Results}

Following the econometric specification presented in Section 2.2, we estimated a nineequation model, consisting of the BMI equation (as a measure of the risk of obesity) and an equation for each of the eight food groups: Cereals; Milk; Eggs; Fat spreads; Meat; Fish; Fruit and vegetables; and Sugars and savoury foods. Estimation was carried out using STATA v.11 statistical package. Estimation used robust standard errors. The estimation procedure, fitted statistics, and specification tests carried out during analysis are presented in the Appendix. These procedures were necessary to test the underlying assumptions and restrictions imposed on the model, and the robustness of the estimation to alternative model specifications.

\footnotetext{
${ }^{5}$ The categories of social class were reduced to just three because of the small size of the sample.
} 
The estimation results are robust to model specification and based on the outcomes of the fitted statistics and tests, presentation of the findings focuses on the results of the SUR estimation ${ }^{6}$. Table 3 reports the results of the joint estimation of the determinants of risk of obesity (as measured by BMI) and food groups. The coefficients, standard errors, and associated level of statistical significance are reported, with the asterisks indicating the level of statistical significance of the $t$-statistics.

The risk of obesity increases significantly with older age and for males, whilst more education, a higher income and higher occupational group reduce the risk. As the older age groups (35 years and above) are consuming significantly more of food groups such as fish, fruit and vegetables, and significantly less of meat, and sugars and savoury foods, then the result indicates that individuals at higher risk of obesity (e.g. as they grow older) may be consuming a healthier diet. It is typical that the BMI-age relation exhibits weight gain until older adulthood (Stunkard and Sobal 1995, Moreira and Padrao 2006).

Males are more likely than females to be at a greater risk of obesity, and this is associated with a higher consumption of all food groups except the healthier food groups (fish and fish products, and fruit and vegetables) which have significantly lower consumption. The diet part of this result is consistent with previous findings that men generally have worse diet than women (e.g. Wardle et al 2004, Abel and McQueen 1994). However, the result for the risk of obesity is surprising, as women are generally perceived as more likely to be obese than men. There are two possible explanations. In the raw data, overweight is higher amongst men (67\%) while obesity is higher amongst women (35\%). Thus, it is possible that the result is reflecting the overweight aspect of risk of obesity. Paeratakul et al (2002) and Martin et al (2008) find similar results in their sample of US and Spanish adults, respectively. Also, the result may be reflecting the endogeneity of food consumption in the gender-obesity relationship, which is rarely considered in previous studies.

The protective effect of higher educational attainment may be mediated by more knowledge and information about healthy eating and associated health benefits ${ }^{7}$. Compared with those with no educational qualification, all other groups consume more of the healthier food groups (fish and fish products, and fruit and vegetables), although the relationship is not uniformly increasing. However, there is less evidence of avoiding unhealthy food groups, with only two categories having significantly lower consumption of meat and all groups consuming more sugars and savoury items. The lower but statistically insignificant risk of obesity for this category of individuals may be reflecting the dominance of the consumption of fish and fish products, and fruit and vegetables over sugars and savoury foods, other things being equal ${ }^{8}$.

\footnotetext{
${ }^{6}$ Whenever there is any discrepancy between SUR and the other estimation results, we will report them.

${ }^{7}$ Both household income and educational qualification were included in the analysis because we believe that they measure different things and are measured at different levels (household and individual level, respectively). The Pearson correlation test suggests a weak correlation between them (0.056).

${ }^{8}$ We test the hypothesis that the obesity-reducing effect of fish, fruit and vegetable is the same as the obesity-increasing effect of sugars and savoury foods and this hypothesis cannot be rejected in all but the degree or vocational equivalent (DegVoc) category: (LowEd: $\mathrm{F}_{(1,1700)}=1.59, p$-value $=0.21$; LowMidEd: $\mathrm{F}_{(1,1700)}=0.68, p$-value $=0.41 ;$ UpMidEd: $\mathrm{F}_{(1,1700)}=0.75, p$-value $=0.39 ; \operatorname{DegVoc}: \mathrm{F}_{(1,1700)}=10.86, p$-value $=$ 0.001 .
} 


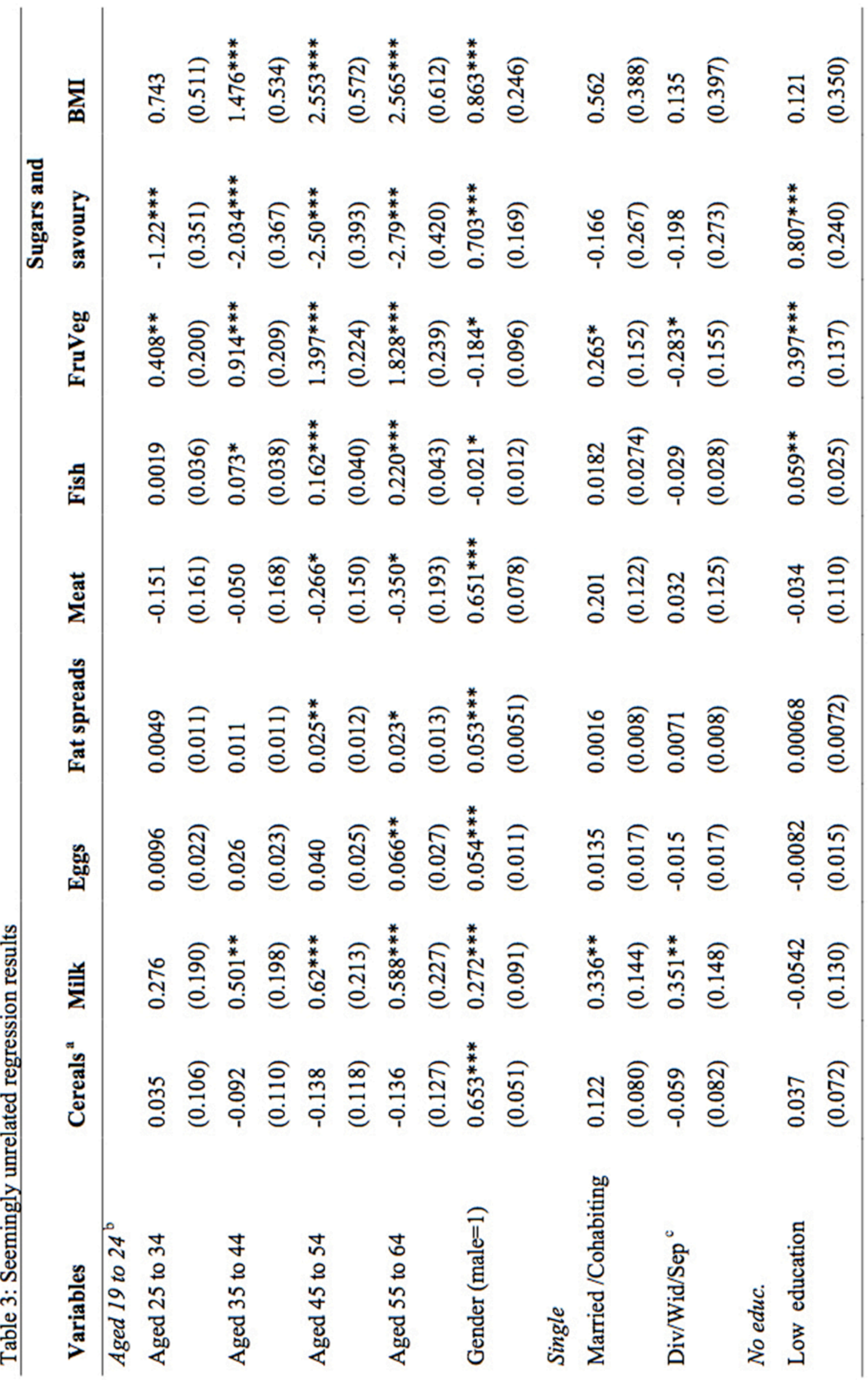




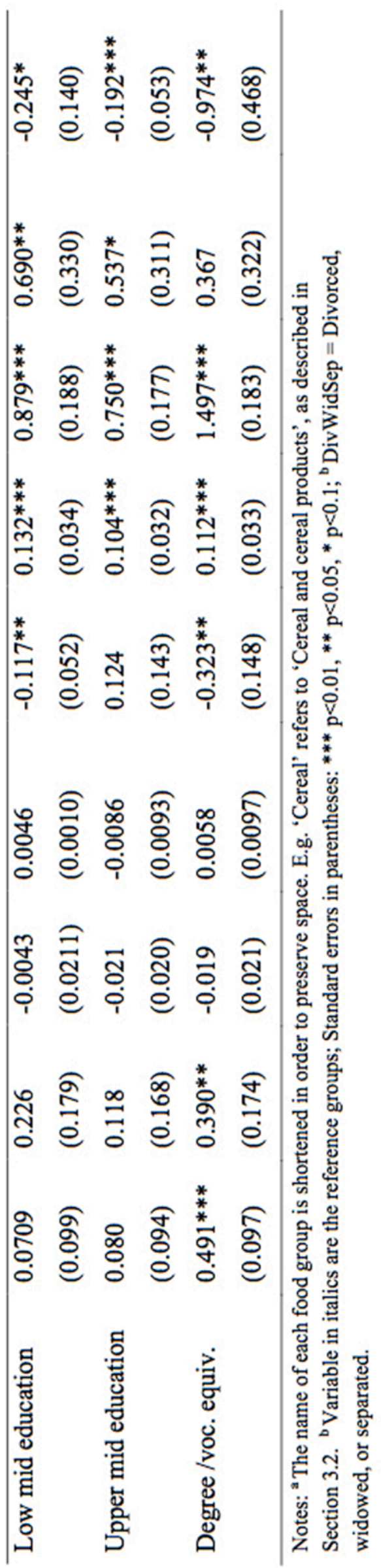




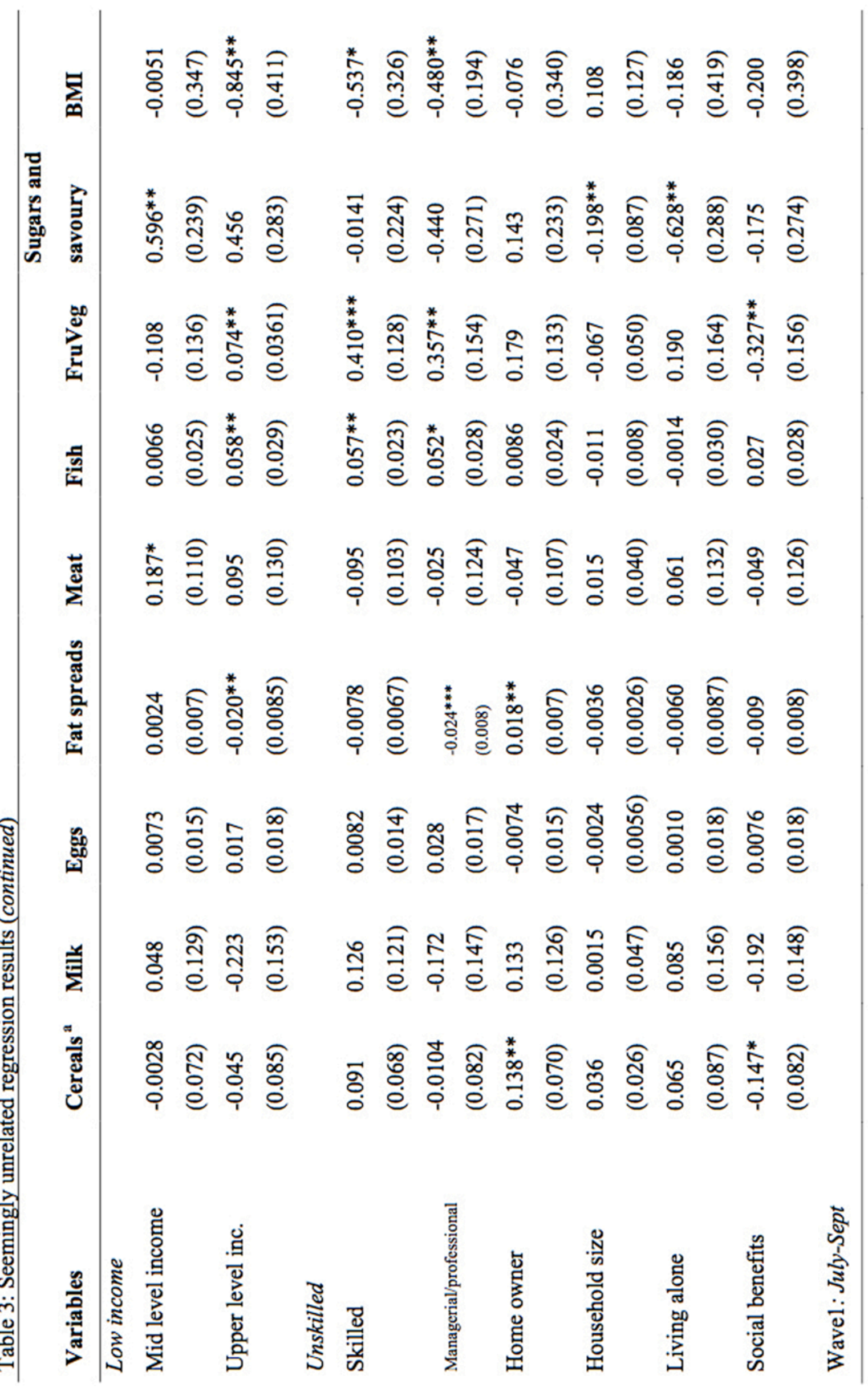




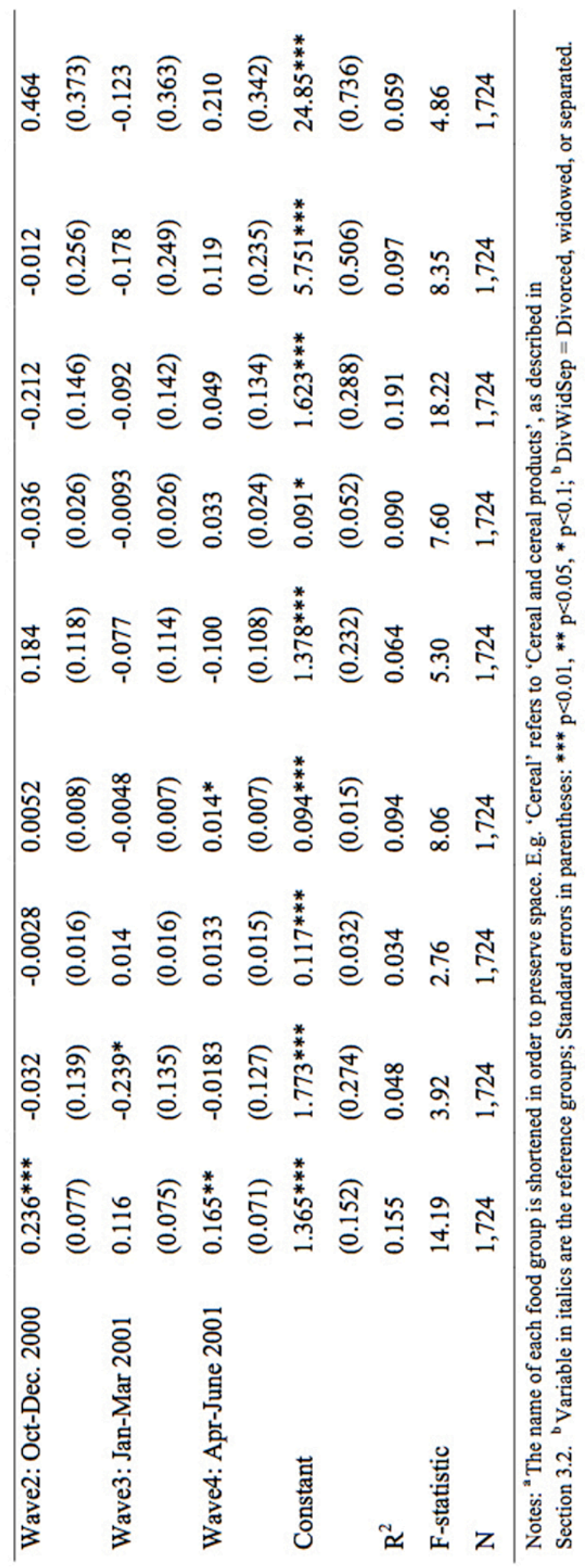


The results on income are similarly mixed. Generally, higher household income is associated with a lower risk of obesity, but the level of statistical significance and the associated food groups differ by income group. Individuals in the middle level household income (i.e. $£ 14,000-£ 30,000$ ) are more likely than those in the reference group (i.e. low household income) to consume meat and meat products, and sugars, preserves and savoury foods, but the associated risk of obesity is statistically not different between these two income groups ${ }^{9}$. On the other hand, individuals at the upper level household income (i.e. at least $£ 30,000$ ) are significantly less likely than those in the reference group to be at risk of obesity, and this is associated with a lower consumption of fat spreads, and a higher consumption of fish, fruit and vegetables. We test the null hypothesis that the coefficients on the household income variables are jointly significantly not different from zero in each of the equations with mixed results ${ }^{10}$. The results seem to suggest that the extent to which the consumption of a healthier diet is expected to the lower risk of obesity may be dependent on the purchasing power of the individual, as indicated by levels of household income.

For occupational social class, the risk of obesity is lowest for skilled workers, followed by the managerial/professional class and this is associated with a higher consumption of fish and fish products and fruit and vegetables. Consumption of meat and meat products, and sugars and savoury foods are also lower but the coefficients are statistically not different from zero across social class groups ${ }^{11}$

None of the other variables has a significant effect on risk of obesity. Household size and living alone were included in order to capture the possible influence of family composition and we find that these variables are associated with a lower consumption of sugars and savoury foods. Individuals in receipt of a social benefit (e.g. income or employment support) are less likely than those who are not to consume cereal and cereal products, and fruit and vegetables.

\section{Discussion}

The present study aimed to contribute to a better understanding of the interrelationships between diet, risk of obesity, and the socioeconomic circumstances of individuals. The objective was to examine whether those groups of individuals in the population at greater risk of obesity can be identified by their pattern of food consumption and associated socioeconomic characteristics, and then targeted for promotion of healthy eating and disease prevention.

Previous studies have found differences in food consumption according to socioeconomic factors, largely because each factor represents different underlying

\footnotetext{
${ }^{9}$ The bootstrap standard errors associated with the coefficients on middle level household income are lower in both the 'Meat and meat products' equation (Std. error $=0.066$ ) and the 'Sugars and savoury foods' equations (Std. error $=0.230$ ), thereby improving the level of statistical significance from $5 \%$ to $1 \%$ level.

${ }^{10}$ Fat spread equation: $\mathrm{F}_{(2,15309)}=6.00, p$-value $=0.0025$, Fish and fish products equation: $\mathrm{F}_{(2,15309)}=3.04, p$ value $=0.004$, Fruit and vegetable equation: $\mathrm{F}_{(2,15309)}=3.12, p$-value $=0.005$, and the BMI equation: $\mathrm{F}_{(2}$, ${ }_{15309)}=3.52, p$-value $=0.0071$.

${ }^{11}$ The bootstrap standard errors associated with the coefficients on skilled and managerial/professional social class are lower in both the 'Fish and fish products' equation (Std. error $=0.021)$ and (Std. error = 0.026), implying an improvement in the level of statistical significance from $5 \%$ to $1 \%$ and from $10 \%$ to $5 \%$ levels, respectively. The standard error associated with the coefficients on skilled social class is also lower in the 'Meat and meat products' equation (Std. error $=0.057$ ), thereby making the effect statistically significant at the $10 \%$ level.
} 
processes through which they affect diet, and the risk of obesity (e.g. Vlismas et al 2009). For example, Moreira and Padrao (2004) using data from Portugal, found the associations between diet and educational attainment to be stronger than the diet-income relation. Whilst education attainment may reflect knowledge and information about healthy eating and associated health benefits, income reflects greater purchasing power. In principle, the results from the present study agree with these previous findings, with an added understanding of how the underlying socioeconomic factors jointly determine diet-health relationship. However, our findings indicate that whilst both income and education were positively associated with healthier foods (e.g. fish/fish products, and fruit and vegetables), and these were associated with lower risk of obesity, only education was positively associated with a reduction in consumption of less healthy foods.

Put in perspective, the economic impact of income appears to be different from its value as a marker of social position, which is also captured by other variables such as education. The first effect which income has is on spending power, for which the standard economic response would be to have more of everything but also we would see substitution effects away from 'inferior' goods. Whilst cereal products may be seen as 'cheap and filling' of which less is consumed as income rises but the health effect is picked up by increasing consumption with education.

In the context of the UK guidelines, healthy eating requires a balanced diet which is achievable; either by consumption of starchy foods (e.g. cereal and cereal products), milk and dairy foods, proteins (e.g. fish, meat, eggs), and fruit and vegetables; by a significant reduction in consumption of less healthy foods (e.g. fatty foods, sugars, preserves and savoury foods); or both (FSA 2010). Our findings indicate however, that the socioeconomic factors associated with these sources of healthy eating might differ. For example, individuals in higher socioeconomic groups (e.g. more educated, higher income, and managerial/professional occupational social class) were associated with healthier foods (e.g. fruit and vegetables). However, the evidence is mixed as to whether this group of individuals were also cutting-down on their consumption of less healthy foods such as fat spreads, sugars, preserves and savoury foods. Thus, specific healthy eating messages may need to be targeted at particular socioeconomic groups in the population.

Our findings also provide an indication that individuals can change their food consumption towards healthier options when their socioeconomic circumstances improve. This was evidenced by the negative correlation between: (i) lower consumption of meat/meat products and higher consumption of fish/fish product; or (ii) lower consumption of meat/meat products and higher consumption of fruit and vegetables.

Finally, the present study differs in certain respects from previous studies that have also examined the relationship between diet and socioeconomic determinants of obesity (e.g. Moreira and Padrao 2004, 2006) ${ }^{12}$, and the recent increasing use of seemingly unrelated regression approach (e.g. Costa-Font and Gil 2005). First, the present study made use of a rich dataset which provides complete food history of the individual in the previous week. We recognise that foods are consumed in complex combinations rather than individually in isolation, which might create multicollinearity problems amongst the food groups. However, the SUR approach adopted in this study allowed the error terms to correlate across the food groups. The SUR approach also ensured that potential endogeneity problems were addressed, which improved the efficiency of the estimates, albeit modestly. These differences may explain a few differences in our findings.

As in previous studies, however, the present study is not without limitations. First, most previous studies using large datasets do find significant gender-specific differences

\footnotetext{
${ }^{12}$ For a comprehensive review of these studies, see Vlismas et al (2009).
} 
in the determinants of obesity (e.g. Ball et al 2002). Due to limitation on the size of our sample, we could not examine the gender-specific effects in this study. We interacted gender with some of the determinants, but we found no statistically significant gender interaction effects.

Secondly, it is well known from previous studies that cross-sectional populationbased surveys may lead to under-representation of some segment of the population such as the disadvantaged groups (e.g. the homeless and the unemployed) (Turell 2000), and individuals living in rural or remote regions. Potential under-representation of the UK population in this data set is a limitation of the study.

Also, under-reporting of food consumption is common in dietary surveys, which has been identified also in other NDNS surveys (e.g. Gregory et al 2000). Under-reporting of food consumption implies that reported food intakes in the survey were more likely to be underestimates (Swan 2004). Rennie et al (2007) estimated the extent of underreporting of energy intake in NDNS 2001 to be approximately $27 \%$ and $29 \%$ amongst men and women, respectively.

However, we took several measures during the analysis to reduce the extent of some of the problems outlined above. These include applying both dietary and interview weights during analysis in order to reduce the extent of under-reporting of food consumption and under-representation, respectively. The SUR estimation of the model also corrected for small sample size.

We recognise that the present study was based on cross-sectional data, which limits the extent to which causality can be inferred. The use of longitudinal or panel data that explore variations in food consumption and the risk of obesity over time can improve the analysis greatly.

\section{Concluding remarks}

Food based policies aimed at addressing the risk of obesity require an understanding of the link between socioeconomic circumstances of people and the diet-obesity relationship. Such an understanding is central to education on healthy eating and disease prevention. The Grossman (1972a) model views the individual as both a consumer and a producer of the commodity health. When individuals make health related lifestyle choices such as food consumption, they simultaneously determine their health outcome such as obesity.

In this study, we explored the view that the relationship between food consumption choices that individuals make and the associated health outcome are jointly affected by some underlying forces some of which are demographic and socioeconomic in nature. We then examined the demographic and socioeconomic factors that may jointly determine food consumption and the risk of obesity (measured by BMI), using the 2000/01 NDNS data set.

Healthy eating is achievable, either by increasing consumption healthy foods such as fruit and vegetables, by cutting down on consumption of less healthy foods such as sugars, preserves and savoury foods, or both. However, our findings indicate that the socioeconomic factors (e.g. income and education) associated with these sources of healthy eating may differ. While increasing household purchasing power may be more effective for increasing consumption of healthier foods such as fruit and vegetables, more knowledge and information about healthy eating may be more effective for cutting down on consumption of less healthy foods (e.g. preserves and savoury foods). An understanding of these different healthy eating contexts is essential for the development of effective targeted food based policies aimed at reducing the risk of obesity. 
However, the findings suggest that healthy eating alone might be insufficient for achieving a significant reduction in the risk of obesity. With a larger data set, we hope to extend the analysis to include physical activity. In this way, we should be able to examine the relative impacts of diet and physical activity on the risk of obesity.

\section{Acknowledgements}

The Health Economics Research Unit of the University of Aberdeen is funded by the Chief Scientific Office of the Scottish Government Health Directorates, Edinburgh. The views expressed in this paper are those of the authors.

* Correspondence to: Damilola Olajide, Research Fellow, Health Economics Research Unit, University of Aberdeen, Foresterhill, Aberdeen, AB25 2ZD, United Kingdom. 


\section{References}

Abel, T. and McQueen, D.V. (1994). Determinants of selected unhealthy behaviours among male and female adults. European Journal of Public Health, 4, pp. 27-32.

Allender, S. and Rayner, M. (2007). The burden of overweight and obesity-related illhealth in the UK. Obesity Reviews, 8, pp. 467-473.

Ball, K., Mishra, G. and Crawford, D. (2002). Which aspects of socioeconomic status are related to obesity among men and women? International Journal of Obesity, 26, pp. $559-565$.

Baum, C.F. (2006). An Introduction to Modern Econometrics Using Stata. Stata Press, Ch. 6.

Breusch, T.S. and Pagan, A.R. (1979). Simple test for heteroscedasticity and random coefficient variation. Econometrica, 47 (5), pp.1287-1294.

CSIRO (2005). The CSIRO Total Wellbeing Diet. Eds.: Noakes, M. and Clifton, P., Penguin Group, Australia.

Chou, S. Y., Grossman, M., and Saffer, H. (2004). An economic analysis of adult obesity: Results from the behavioural risk factor surveillance system. Journal of Health Economics, 23, pp. 565-587.

Costa-Font, J and Gil, J. (2005). Obesity and the incidence of chronic diseases in Spain: A seemingly unrelated probit approach. Economics and Human Biology, vol. 3, pp. 188214.

Eberth, B. \& Smith, M. D. (2010). Modelling the participation decision and duration of sporting activity in Scotland. Economic Modelling, 27 (4): 822 - 834.

EMIS (2009). Recommended safe units of alcohol. Egton Medical Information Systems Ltd. DocID 4625, Version 39. Available from http://www.patient.co.uk//showpdffs/pilsL517. [Accessed February 16, 2010].

Field, A. (2005). Discovering statistics using SPSS (2 ${ }^{\text {nd }}$ edition). London: Sage. Chpt. 5.

Flegal, K.M., Troiano, R. P., Pamuk, E. R., Kuczmarski, R. J., and Campbell, S.M. (1995). The influence of smoking cessation on the prevalence of overweight in the United States. The New England Journal of Medicine, vol. 333 (18), pp.1165-1170.

Food Standards Agency (2010). Eat Well: your guide to healthy eating. Available from http://www.food.gov.uk/multimedia/pdfs/publication/eatwell0708.pdf.[ Accessed May 27,2011].

Gallant, A. R. (1987). Non-Linear Methods in Econometrics. In Eatwell, Murray, J. M. and Newman, P. (eds.). The New Palgrave, 3, (K-P), Stockton Press, New York, pp. 663-666.

Gregory, J., Lowe, S., Bates, C.J., Prentice, A., Jackson, L.V., Smother, G., Wenlock, R., and Farron, M. (2000). National Diet and Nutrition Survey: Young People Aged 4-18 years, vol.1: Report of the Diet and Nutrition Survey. London: The Stationary Office.

Grossman, M. (1972a). The demand for health: A theoretical and empirical application. NBER, New York.

Grossman, M. (1972b). On the concept of health capital and the demand for health', Journal of Political Economy, 80, pp. 223-255. 
Hausman, J. A. (1978). Specification tests in econometrics. Econometrica, 46, pp. 12511271.

H. Lee Moffit Cancer Centre and Research Institute (2000). Smoking and Weight: A guide to remaining smoke free. Booklet 3, I/00-RL-6, H.Lee Moffit Cancer Centre and Research Institute, University of South Florida. Available from http://www.smokefree.gov/pubs/FFree3.pdf. [Accessed 27 July 2010).

House of Commons Health Select Committee (2004). Obesity: Third Report of Session 2003/04. The Stationery Office: London.

Jackson, J.E. (2003). A User's Guide to Principal Components. New York: Wiley

Joliffe, I. T. (2002). Principal Component Analysis. $2^{\text {nd }}$ Edition, New York: Ch.5.

King, G., Tomz, M., and Wittenberg, J. (2000). Making the most of statistical analysis: Improving interpretation and presentation. American Journal of Political Science, 44, (2), pp. 347-361.

Klerk, M., Jansen, M.C.J.F., Van't Veer, P., and Kok, F.J. (1998). Vegetables and fruits in chronic disease prevention. Division of Human Nutrition and Epidemiology, Wageningen Agricultural University. The Nederland, pp. 70.

Kral, T. Stunkard, A.J., Berkowitz, R.I., Stallings, V.A., Brown D. D., and Faith, M.S. (2007). Daily food intake in relation to dietary energy density in the free-living environment: A prospective analysis of children born at different risk of obesity. American Journal of Clinical Nutrition, 86, pp. 41-47.

Lakdawalla, D. and Philipson, T. (2002). The growth of obesity and technological change: A theoretical and empirical Examination. NBER Working Paper No. 8946. Available at http://www.nber.org/papers/w8946.pdf. [Accessed 17 May 2009].

McCormick, B. and Stone, I. (2007). Economic costs of obesity and the case for government intervention. Obesity Reviews, 8(s1), pp. 161-164.

Martín, A. R., Manuel, Nieto, J.M.M, Ruiz, J.P.N., and Jiménez, L.E. (2008). Overweight and obesity: The role of education, employment and income in Spanish adults. Appetite, 51, pp. 266-272,

Moreira, P., and Padrao, P. (2004). Educational and economic determinants of food intake in Portuguese adults: A cross-sectional survey', BioMed Central Public Health, 4, pp. 58.

Moreira, P., and Padrao, P. (2006). Educational, economic and dietary determinants of Obesity in Portuguese adults: A cross-sectional study', Eating Behaviours, 7, pp. 220228.

Morris, S. (2007). The impact of obesity on employment. Labour Economics, vol.14, pp. 413-433.

National Diet and Nutrition Survey (NDNS) (2002). National Diet \& Nutrition Survey: adults aged 19 to 64 years. User Guide, London: Her Majesty's Stationery Office.

Nayga, R. M. Jr., Beverly, J. T., and Rosenzweig, L. (1999). Assessing the importance of health and nutrition related factors on food demand: a variable Preference Investigation. Applied Economics, 31, pp.1541-1549.

Nayga, R. M., Jr. (2008). Nutrition, obesity and health: Policies and economic research challenges. European Review of Agricultural Economics, vol. 35 (3), pp. 281-302. 
Newby, P.K., Tucker, K.L., Wolk, A. (2005). Risk of overweight and obesity among semivegetarian, lactovegetarian, and vegan women. American Journal of Clinical Nutrition, 81, pp. 1267-1274.

Paeratakul, S., Lovejoy, J.C., Ryan, D.H., and Bray, G.A. (2002). The relation of gender, race and socioeconomic status to obesity and obesity comorbidities in a sample of US adults. International Journal of Obesity, 26, pp. 1205-1210.

POST (2003). Improving children's diet. Report No. 199. Parliamentary Office of Science and Technology. London. Available from http://www.parliament.uk/documents/post/pr199.pdf. Chapter 2.

Pescatello, L.S. and VanHeest, J.L. (2000). Physical activity mediates a healthier body weight in the presence of obesity. British Journal of Sports Medicine, 34, pp. 86-93. Available from http://bjsportmed.com/content/34/2/86.full.pdf. [Accessed 17 May 2009]

Rennie, K.L., Coward, A. and Jebb, S.A. (2007). Estimating under-reporting of energy intake in dietary surveys using an individualised method. British Journal of Nutrition, 97, pp. 1169-1176.

Sobal, J. and Stunkard, A.J. (1989). Socioeconomic status and obesity: A review of the literature', Psychological Bulletin, 105 (2), pp. 260-275.

Stunkard, A.J. and Sobal, J. (1995). Psychological consequences of obesity. In: Eating disorders and obesity: A comprehensive handbook. Ed: Brownell, K.D. and Fairburn, C.G. The Guildford Press, New York.

Swan, G. (2004). Findings from the latest National Diet and Nutrition Survey. Proceedings of the Nutrition Society, 63, pp. 505-512.

Tomz, M., J. Wittenberg, and G. King (2003). Clarify: Software for interpreting and presenting statistical results. Version 2.1. Stanford University, University of Wisconsin, and Harvard University. Available at http://www.jstatsoft.org/v08/i01/paper. [Accessed 20 April 2008].

Turrell, G. (2000). Income-reporting: Implications for health inequalities research. Journal of Epidemiology and Community Health, 54, pp. 207-214.

Variyam, J.N., Blaylock, J., and Smallwood, D. (1996). A Probit latent variable model of nutrition information and dietary fibre intake. American Journal of Agricultural Economics, vol. 78 (3), pp. 628-639.

Vlismas, K., Stavrinos. V. and Panagiotakos, D.B. (2009). Socio-economic status, dietary habits and health-related outcomes in various parts of the World: A review. Central European Journal of Public Health, 17 (2), pp. 55-63.

Wardle, J., Haase, A.M., Steptoe, A., Nillapun, M., Jonwutiwes, K., and Bellisie, F. (2004). Gender differences in food choice: The contribution of health beliefs and dieting. Annals of Behavioural Medicine, vol. 27 (2), pp. 107-116.

Wamala, S.P., Alicja Wolk, D., and Orth-Gomer, K. (1997). Determinants of obesity in relation to socioeconomic status among middle-aged Swedish women. Preventive Medicine, vol. 26 (5), pp.734-744.

Wang, Y., Monteiro, C., and Popkin, B.M. (2002). Trends of obesity and underweight in older children and adolescents in the United States, Brazil, China and Russia. American Journal of Clinical Nutrition, 75, pp. 971-977. 
Whichelow, M.J., and Prevost, A.T. (1996). Dietary patterns and their associations with demographic, lifestyle and health variables in a random sample of British adults. British Journal of Nutrition, 76, pp. 17-30.

Wilson, M. G. (2002). Cigarette smoking and weight loss in nursing home residents. The International Journal of Medicine [Medicine-Online]. Available from: http://www.priory.com/med/cigsmoking.htm. [Accessed 22 March 2010].

World Health Organisation (2004). Global Strategy on Diet, Physical Activity and Health. World Health Organisation. Available from: http://www.who.int/dietphysicalactivity/strategy/eb11344/strategy english_web.pdf. [Accessed 14 October 2009].

Yang, E.J., Kerver, J.M., Song, W.O. (2005). Dietary patterns of Korean Americans described by factor analysis. Journal of American College of Nutrition, 24, pp. 115121. Available at http://www.jacn.org/cgi/reprint/24/2/115. [Accessed 5 June 2009].

Zellner, A. (1962). An efficient method of estimating seemingly unrelated regressions and tests of aggregation bias. Journal of the American Statistical Association, 57, pp. 500509. 